\title{
$\mathrm{BESS}$ 모델링 및 전기철도 급전계통에의 전압보상 적용
}

\section{BESS Modeling and Application to Voltage Compensation of Electric Railway System}

\author{
유 형 준*·손 호 익*·김 학 만 ${ }^{\dagger}$ \\ (Hyeong-Jun Yoo $\cdot$ Ho-Ik Son $\cdot$ Hak-Man Kim)
}

\begin{abstract}
The load of electric railroad can generate voltage fluctuation in the electric railway system because of high speed of the electric railroad and frequent movement and stop. This voltage fluctuation of electric railway system can cause not only voltage imbalance but also harmonic in the utility grid. Therefore the electric railroad system is in need of the reactive power compensation, such as static synchronous compensator (STATCOM) and static var compensator (SVC). Especially, the battery energy storage system (BESS) can control the real and reactive power at the same time. In this paper, the electric railway system using BESS has been modeled to show its voltage compensation effect using Matlab/Simulink.
\end{abstract}

Key Words : Scott transformer, Electric railway system, Battery energy storage system (BESS)

\section{1. 서 론}

국내에서 운행되고 있는 대부분의 전기철도는 단상 $50 \mathrm{kV}$ 로 운행되기 때문에 한국전력공사(이하 한전)로부터 수전받 은 3상 $154 \mathrm{kV}$ 를 단상 $50 \mathrm{kV}$ 로 변환하여 사용되고 있다. 이러한 전기철도는 3상 전력계통의 관점에서 볼 때 단상 집 중부하로써 불평형 부하로 작용되며 전력계통의 효율을 저 하시킬 수 있다. 따라서 이러한 문제점을 보완하기 위하여 3 상의 전력을 2 기의 단상 교류전력으로 변환시켜 단상부하를 3 상 평형부하에 가깝게 할 수 있는 스코트 변압기를 사용하고 있다[1-3].

그러나 전기철도의 빈번한 이동과 정지, 고속화와 견인력 증가 등의 이유로 전기철도 부하는 부하변동이 극심한 전기 적 특성을 가지고 있어 전기철도의 이동과 정지에 따라 전 기철도 급전시스템의 전압변동이 발생한다[3,4]. 이러한 전압 변동은 3상 전력계통의 전압 불평형, 고조파 발생과 같은 전 력품질 저하 문제를 일으켜 계통에 악영향을 발생시키므로 $\mathrm{STATCOM}, \mathrm{SVC}$ 와 같은 무효전력 공급 장치 적용에 대한 연구가 활발히 진행되고 있다[3-5].

한편, 전세계적으로 배터리 에너지 저장장치 시스템 (BESS, battery energy storage system)에 관한 연구가 활 발히 진행되고 있고, 이를 이용한 전력계통에의 적용이 폭넓 게 연구되고 있다[6-8]. 특히, $\mathrm{BESS}$ 는 유·무효전력을 동시 에 제어할 수 있어 전기철도 급전계통의 전압제어에도 효과 적일 것으로 판단된다. 종래의 $\mathrm{BESS}$ 는 납 배터리 기반이었 지만 짧은 수명과 에너지밀도 측면에서 단점이 있어 최근에 는 리튬이온 기반의 $\mathrm{BESS}$ 적용에 대한 연구가 활발히 진행

\footnotetext{
* Dept. of Electrical Engineering, Univ. of Incheon, Korea

+ Corresponding Author: Dept. of Electrical Engineering, Univ. of Incheon, Korea

E-mail : hmkim@incheon.ac.kr
}

Received : January 16, 2013; Accepted : February 25, 2013
되고 있다[9-11].

본 논문에서는 리튬이온 배터리를 이용한 $\mathrm{BESS}$ 를 모델 링하고, 모델링한 $\mathrm{BESS}$ 에 의한 전기철도급전시스템의 전압 보상효과를 검토하고자 한다.

\section{2. 전기철도 급전 시스템}

전기철도 급전시스템은 3 상 $154 \mathrm{kV}$ 를 수전하여 2 기의 단 상 교류 $50 \mathrm{kV}$ 로 강압하여 전차선에 전원을 공급하는 단권 변압기(AT, auto transformer)방식과 전철변전소에서 3상 $66 \mathrm{kV}$ 를 수전하여 단상 교류 $25 \mathrm{kV}$ 로 강압하여 전차선에 전원을 공급하는 흡상변압기(BT, booster transformer)방식 으로 나눌 수 있다[12]. 한편 국내에서 운행되고 있는 대부 분의 전기철도는 그림 1 과 같은 $\mathrm{AT}$ 급전시스템을 사용하고 있어 본 논문에서는 AT 급전시스템에 대한 내용을 다룬다.

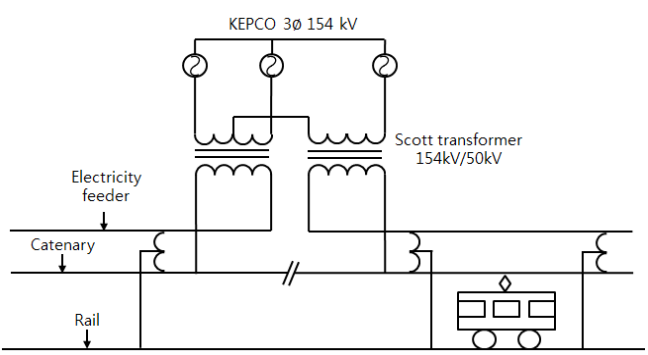

그림 1 AT 급전시스템

Fig. 1 AT railway system

일반적으로 대용량 단상부하에 3상 전력을 공급할 경우, 3 상 전력은 불평형이 발생하고 불평형은 역상전류, 회전기 손실 등을 일으키므로 3상 전력계통의 관점에서 단상부하를 볼 경우 악성 부하가 된다. 스코트변압기는 이러한 문제점 을 해결하기 위하여 사용되는 변압기이다. 
스코트변압기는 그림 2 와 같이 2 기의 단상 변압기를 사용 한다. 이 때 $\mathrm{M}$ 상 변압기의 양 단자와 $\mathrm{T}$ 상 변압기 1 차권선 의 $\sqrt{3} / 2=0.866$ 되는 지점에서 인출된 단자는 $\mathrm{A}, \mathrm{B}, \mathrm{C}$ 상에 각 각 연결되고, $\mathrm{M}$ 상과 $\mathrm{T}$ 상의 변압기 2 차측에서는 1 차측 권선 에 대응하는 전압이 유기된다. 이와 같이 결선된 2 기의 단 상 변압기는 전기철도계통에 방면별 또는 상하선별로 전력 을 공급한다[12].

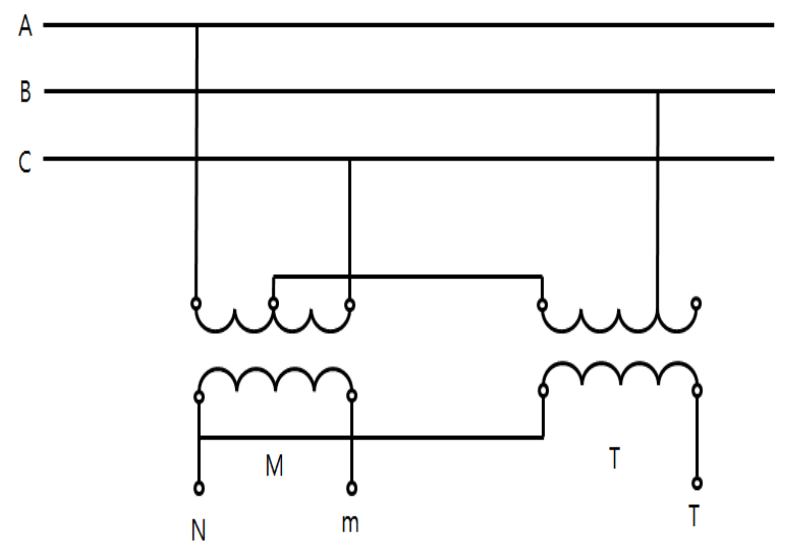

(a) Concept diagram of scott transformer

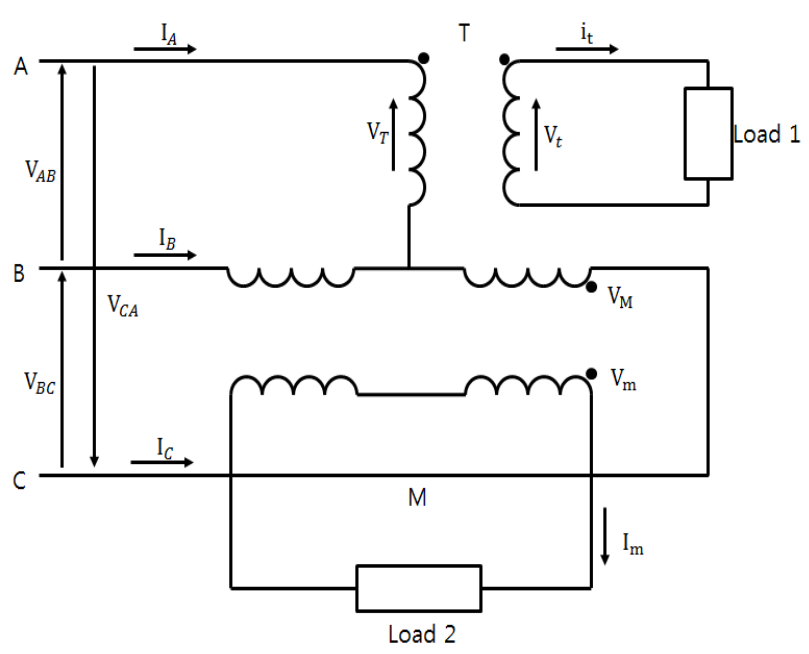

(b) Connection diagram of scott transformer

그림 2 스코트 변압기

Fig. 2 Scott transformer

이러한 스코트변압기는 3상 전력을 2기의 단상교류로 변 환하며, 이 때 변환하여 얻은 두 개의 단상은 $\mathrm{M}$ 상, $\mathrm{T}$ 상으로 구분하고, $90^{\circ}$ 의 위상 차이를 가지고 있어 각 상은 전기적으 로 연결되지 않는다.

또한 스코트변압기는 결선방식에 의하여 2차측에 용량 및 역률이 같은 부하가 접속되면 1차측의 3상에는 평형전류가 유입되어 불평형이 0이 되는 특징을 가지고 있다[12,13]. 이 때 $\mathrm{M}$ 상과 $\mathrm{T}$ 상에 동일한 부하를 접속한 경우 1 차 측인 3 상 전류의 크기는 $2 I_{T} / \sqrt{3}$ 이며, 위상각이 $120^{\circ}$ 차이가 나는 3 상 평형전류가 흐르게 된다[13,14].
그러나 스코트변압기를 통하여 생성된 2기의 단상전력은 방면별, 상하선별로 공급되어 운영되며, 전기철도의 이동과 정지 또는 전차선에서 운전되는 전차 수에 의하여 $\mathrm{M}$ 상과 $\mathrm{T}$ 상의 부하는 서로 다른 용량 및 역률을 가지게 된다. 따라 서 전기철도 급전시스템에 스코트변압기를 사용하더라도 $\mathrm{M}$ 상, $\mathrm{T}$ 상의 부하 평형조건을 만족시킬 수 없어 3상 전력계통 에서는 전압 불평형이 발생하게 된다.

\section{BESS 모델링 및 전압보상}

본 논문에서는 리튬이온 $\mathrm{BESS}$ 를 이용하여 전기철도 급 전시스템의 부하변동 시 전압변동 보상 효과를 검토하였다. 이때, $\mathrm{BESS}$ 의 충/방전을 위한 전력변환장치로는 단상 풀브 리지 컨버터를 사용하였다.

\section{1 배터리 모델}

리튬이온 배터리는 그림 3 과 같이 가변전원과 고정 저항 을 이용한 비선형 배터리 모델을 사용하였다[15].

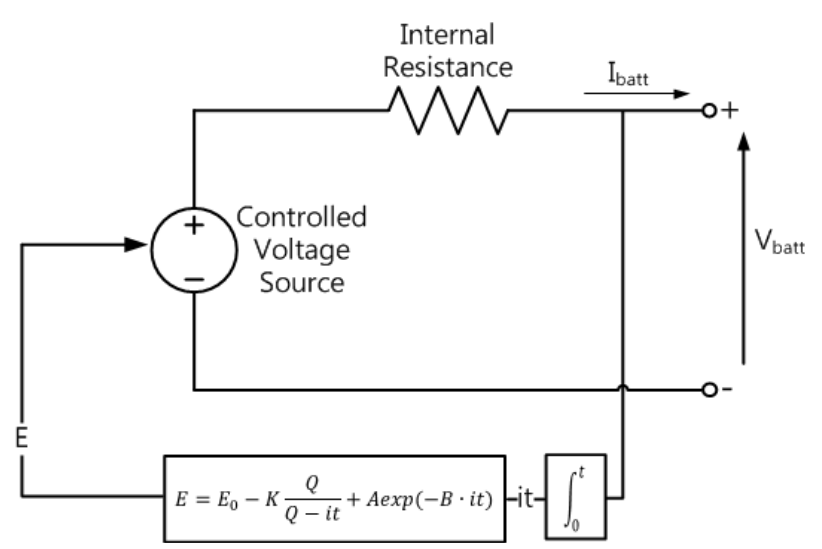

그림 3 배터리모델

Fig. 3 Battery model

배터리의 전원은 그림 3 과 같이 배터리에 흐르는 전류를 측정한 후 식 (1)를 통하여 계산된 값이 가변전원에 입력된 다[15].

$$
E=E_{0}-K \frac{Q}{Q-i t}+A \exp (-B \cdot i t)
$$

여기서, $\int i d t$ : 배터리 충전전류 $(\mathrm{Ah})$

$A:$ 지수함수에서의 크기 $(\mathrm{V})$

$B$ : 지수함수에서의 역 시상수 $(\mathrm{Ah})^{-1}$

$V_{\text {batt }}$ : 배터리 전압 $(\mathrm{V})$

$R$ : 내부 저항 $(\Omega)$

$i$ : 배터리 전류 $(\mathrm{A})$

또한 위의 배터리모델은 배터리의 전류가 흐르지 않거나 풀 방전된 상태에서의 전압은 0에 가깝게 된다. 이는 실제 배터리모델의 특성을 반영한 결과이다. 


\section{2 단상 전압형 컨버터}

본 논문에서의 $\mathrm{BESS}$ 는 그림 4 와 같이 양방향 전력변환 이 가능한 IGBT (insulated gate bipolar transistor) 기반의 단상 전압형 컨버터를 사용하였고, 이는 정현파 $\mathrm{PWM}$ (pluse width modulation)을 이용하여 전류제어를 하였으며, 배터리, $\mathrm{DC}$ 링크, 풀 브릿지, $\mathrm{L}$ 필터로 구성되어 있다.

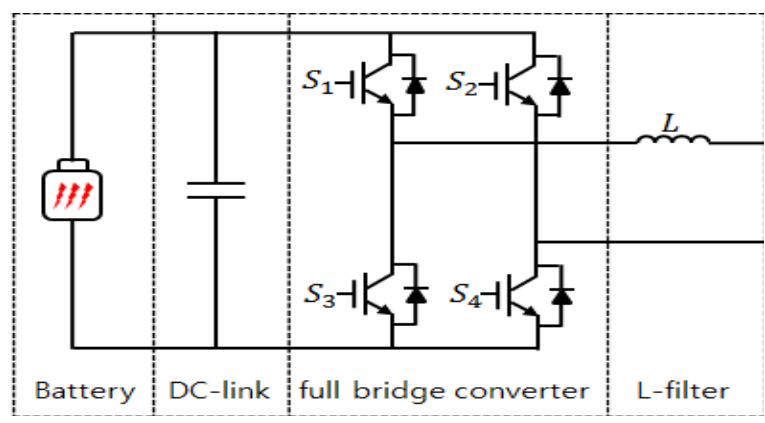

그림 4 단상 전압형 컨버터

Fig. 4 Single-phase voltage source converter

정현파 $\mathrm{PWM}$ 을 이용하여 단상 풀브리지 컨버터틀 제어 할 때, 각 폴의 스위칭은 그림 5 와 같이 $180^{\circ}$ 위상차를 가지 는 두 개의 기준파와 하나의 반송파에 의하여 이루어지며 $180^{\circ}$ 의 위상차이에 의하여 식 (2)와 같은 폴 전압이 생성되 며 이에 식 (3)과 같은 출력전압을 얻을 수 있다[16].

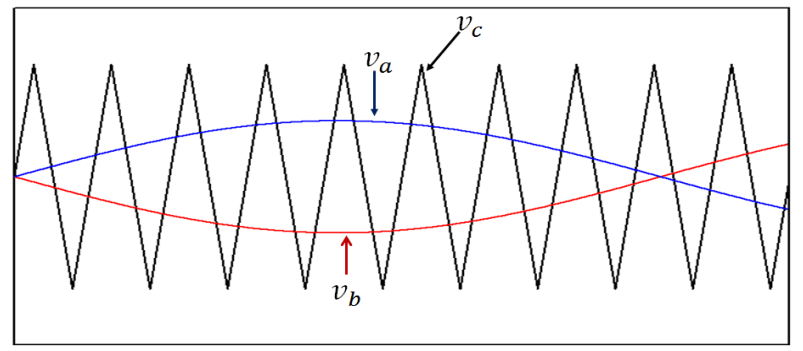

그림 5 스위칭 순간의 기준파와 반송파

Fig. 5 Reference wave and carrier wave

$$
v_{a}=\frac{V_{D C}}{2} m_{a} \sin (w t)=-v_{b}
$$

$$
\begin{aligned}
& \text { 여기서, } V_{D C} \text { : 입력 } \mathrm{DC} \text { 전원 } \\
& v_{a}, v_{b} \text { : 폴전압 } \\
& v_{c}: \text { 반송파 } \\
& m_{a}: \text { 변조지수 }\left(=\frac{\text { 기본파의진폭 }}{\text { 반송파의진폭 }}\right) \\
& v_{o}=v_{a}-v_{b}=V_{D C} m_{a} \sin u t \quad\left(\text { 단, } 0 \leq m_{a} \leq 1\right)
\end{aligned}
$$

식 (3)을 통하여 단상 풀브리지 컨버터의 출력전압 $v_{o}$ 의 최대값은 $m_{a}$ 가 1 보다 작은 선형변조구간에서 $(1 / \sqrt{2}) V_{D C} m_{a}$
$\mathrm{V}$ 된다는 것을 확인할 수 있다. 따라서 전기철도 급전시스 템에 $\mathrm{BESS}$ 를 적용할 경우 컨버터의 출력전압에 따른 배터 리의 전압을 고려한 후 컨버터를 설계해야 한다.

\section{3 단상 전압형 컨버터의 제어기 설계}

본 논문에서는 시간에 따라 변동하는 교류 물리값을 간단 하게 제어할 수 있는 $\mathrm{dq}$ 프레임에서의 제어법을 이용하여 전압형 컨버터의 전류를 제어한다.

그러나 일반적으로 $\mathrm{dq}$ 변환을 하기 위해서는 최소 2 개 이 상의 상이 필요하지만 단상 교류 시스템은 1 개의 상만 존재 하므로 일반적인 $\mathrm{dq}$ 변환과 달리 그림 6 과 같이 실제회로에 대하여 $90^{\circ}$ 위상 차이를 가지는 가상의 직교회로를 생성하 여 dq변환을 하는 방법을 사용한다. 이 때 실제회로와 가상의 직교회로는 위상지연 시킬 뿐 파라미터는 모두 동일하다[17].

그림 6 과 같은 회로에 의하여 실제회로에 흐르는 전류와 $90^{\circ}$ 위상차이를 가지는 가상의 직교전류를 생성할 수 있다.

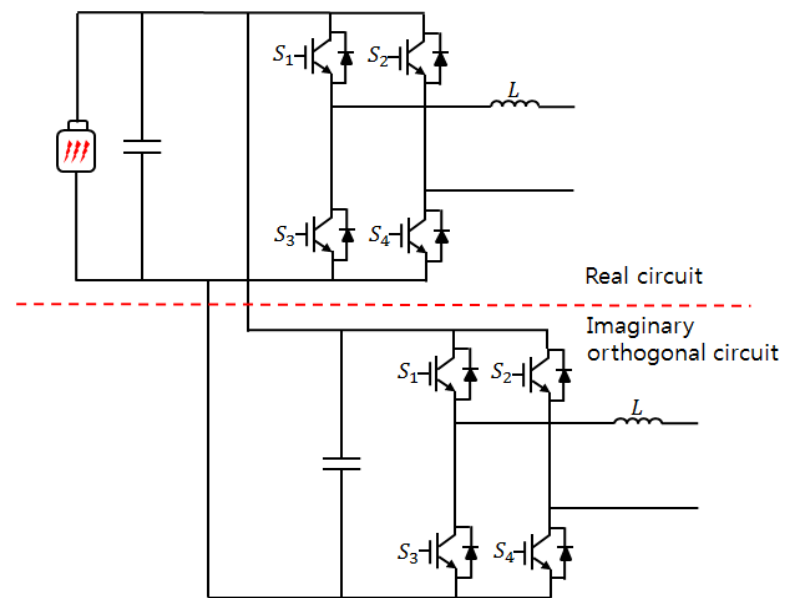

그림 6 실제회로와 가상의 직교회로

Fig. 6 Real circuit and imaginary orthogonal circuit

또한, 식 (4)에 회전행렬인 식 (5)를 적용하면 식 (6)과 같 이 $\mathrm{dq}$ 변환된 전류를 얻을 수 있다. 또한 단상전류의 $\mathrm{dq}$ 변환 은 그림 7과 같은 블록도로 나타낼 수 있다[17].

$$
\begin{aligned}
& I_{R}=I_{m} \sin (w t+\phi) \\
& I_{I}=I_{m} \cos (w t+\phi)
\end{aligned}
$$

$$
\begin{gathered}
\text { 여기서, } I_{R} \text { : 실제전류 } \\
I_{I} \text { : 가상전류 } \\
I_{m} \text { : 전류의 크기 } \\
T=\left[\begin{array}{rr}
\cos w t & \sin w t \\
-\sin w t & \cos w t
\end{array}\right] \\
{\left[\begin{array}{l}
I_{D} \\
I_{Q}
\end{array}\right]=T\left[\begin{array}{l}
I_{R} \\
I_{I}
\end{array}\right]=\left[\begin{array}{rr}
I_{R} \cos w t & I_{I} \sin w t \\
-I_{R} \sin w t & I_{I} \cos w t
\end{array}\right]}
\end{gathered}
$$

한편 그림 6 과 같은 실제회로와 가상의 직교회로를 그림 8 의 (a)와 같이 등가모델로 구성할 수 있고, $\mathrm{dq}$ 변환을 적용한 
$\mathrm{dq}$ 프레임에서의 등가모델은 그림 8의 (b)와 같이 나타낼 수 있다. 이때 $\mathrm{dq}$ 프레임에서의 등가모델은 식 (7)과 같은 전압 방정식으로 나타낼 수 있다[17-20].

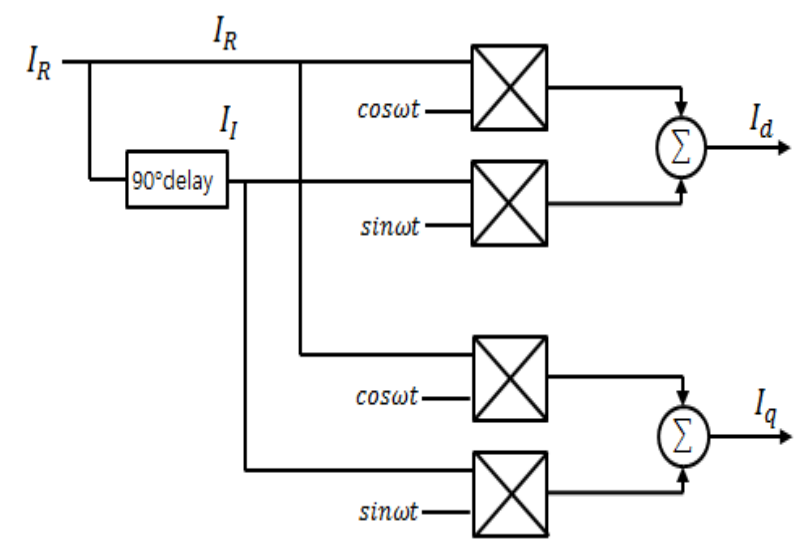

그림 7 단상 $\mathrm{dq}$ 변환 블록도

Fig. 7 Single-phase dq transformation block diagram

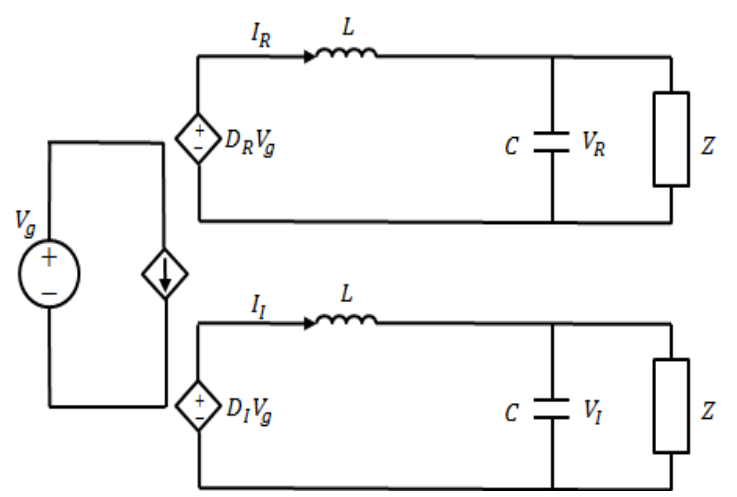

(a) Equivalent model of real and imaginary orthogonal circuit

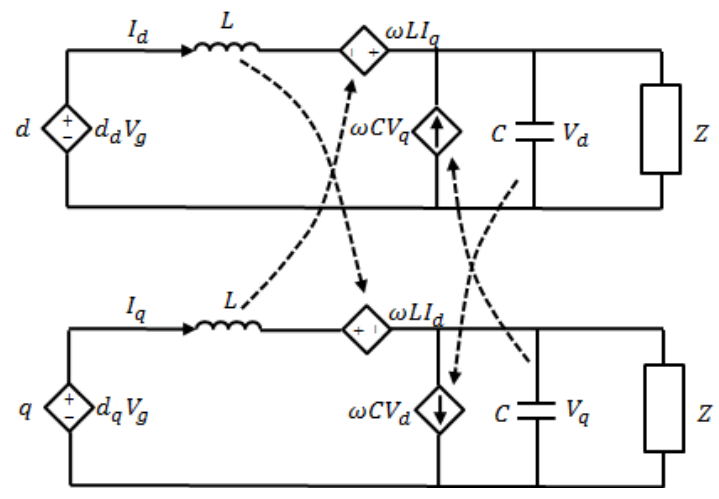

(b) Equivalent model in the dq rotating frame

그림 8 전압형 컨버터 등가모델

Fig. 8 Equivalent circuit of voltage source converter

따라서 식 (7)과 같이 $\mathrm{dq}$ 프레임에서의 등가모델에서 전압 방정식을 이용하여 그림 9 와 같은 전류제어기를 설계할 수 있다[17].

$$
\begin{aligned}
& \frac{d}{d t}\left[\begin{array}{c}
I_{d} \\
I_{q}
\end{array}\right]=\frac{V_{g}}{L}\left[\begin{array}{c}
d_{d} \\
d_{q}
\end{array}\right]+\left[\begin{array}{cc}
0 & w \\
-w & 0
\end{array}\right]\left[\begin{array}{c}
I_{d} \\
I_{q}
\end{array}\right]-\frac{1}{L}\left[\begin{array}{c}
V_{d} \\
V_{q}
\end{array}\right] \\
& \frac{d}{d t}\left[\begin{array}{c}
V_{d} \\
V_{q}
\end{array}\right]=\frac{1}{C}\left[\begin{array}{c}
I_{d} \\
I_{q}
\end{array}\right]+\left[\begin{array}{cc}
0 & w \\
-w & 0
\end{array}\right]\left[\begin{array}{c}
V_{d} \\
V_{q}
\end{array}\right]-\frac{1}{Z C}\left[\begin{array}{c}
V_{d} \\
V_{q}
\end{array}\right]
\end{aligned}
$$

여기서, $\mathrm{L}$ : 인덕턴스

$\mathrm{C}:$ 커패시턴스

Z : 부하임피던스

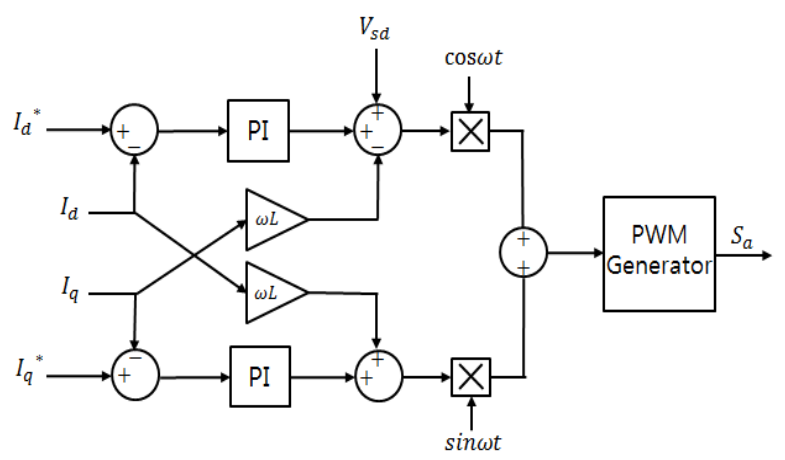

그림 9 전류제어기 블록도

Fig. 9 Current controller block diagram

이와 같은 방법으로 설계한 전류제어기를 이용하여 그림 10 과 같은 $\mathrm{BESS}$ 를 구성할 수 있다.

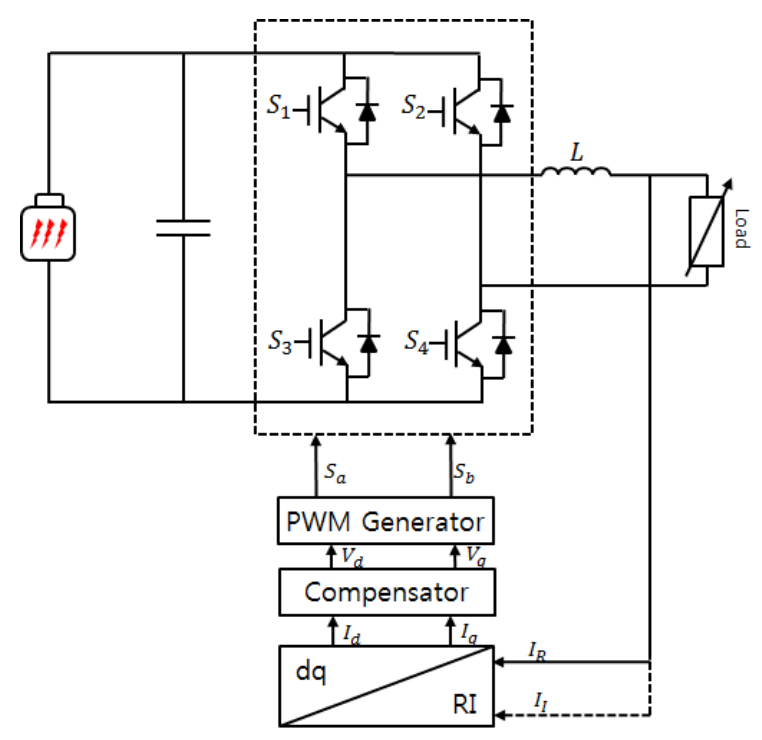

그림 10 단상 BESS

Fig. 10 Single-phase BESS

\section{$3.4 \mathrm{BESS}$ 를 이용한 급전 시스템 구성}

그림 11 은 전기철도 급전시스템에 $\mathrm{BESS}$ 를 적용한 전체 구성도이며 스코트변압기, 단상 $\mathrm{BESS} 2$ 기, 가변부하로 구성 되어 있다. 


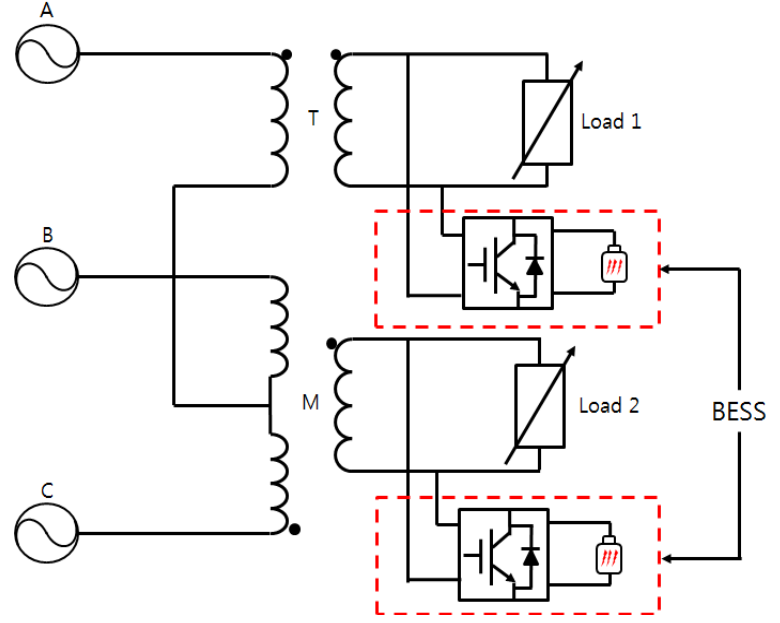

그림 $11 \mathrm{BESS}$ 를 적용한 전기철도 급전 시스템 구성도

Fig. 11 Electric railway system using the BESS

\section{4. 시뮬레이션}

본 논문에서는 Matlab/Simulink를 이용하여 리튬이온 배 터리를 이용한 $\mathrm{BESS}$ 를 모델링하였으며, 그림 11 과 같이 모 델링된 $\mathrm{BESS}$ 를 적용한 전기철도 급전시스템을 구성하였다. 또한 전기철도 급전시스템의 전압이 유지되는지를 테스트하 기 위하여 4초 간격으로 단계별 부하를 추가해가며 시뮬레 이션하였다.

먼저 전기철도 급전시스템에 별도의 전압보상장치가 없을 경우 전기철도 급전시스템에 단계별 부하를 증가시키게 되 면 그림 12 와 같이 부하의 증가에 따라 전압강하가 발생하 는 것을 확인할 수 있다.

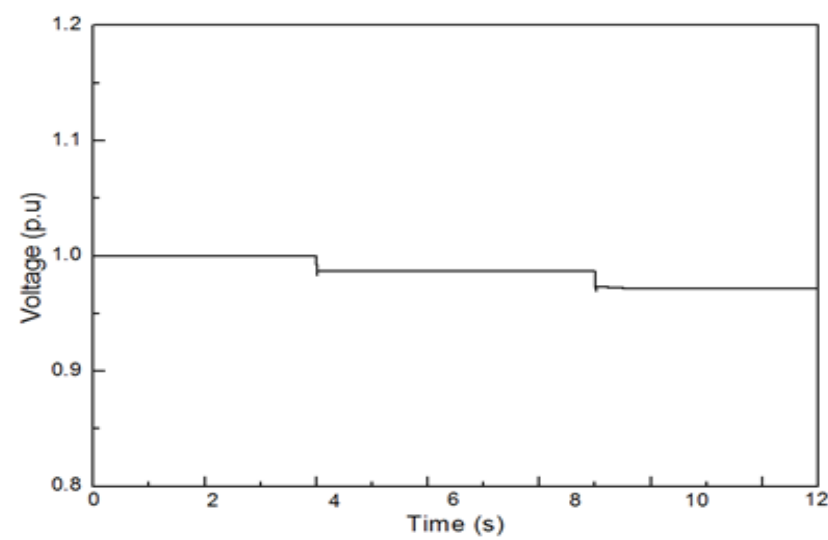

그림 $12 \mathrm{BESS}$ 를 적용하지 않을 경우 부하변동에 따른 전압 Fig. 12 Voltage by load change without BESS

또한, 전기철도 부하가 변동할 경우 3상 전력계통의 전압 은 그림 13 과 같이 전압 불평형이 발생하게 된다. 그러나 그림 11 과 같이 전기철도 급전시스템에 $\mathrm{BESS}$ 를 적용할 경 우 전기철도 급전시스템에 단계별 부하를 추가하더라도 그 림 14 와 같이 $\mathrm{BESS}$ 에 의하여 무효전력이 공급됨으로써 전 압이 1 p.u로 유지되는 것을 그림 15 을 통하여 확인할 수 있다.

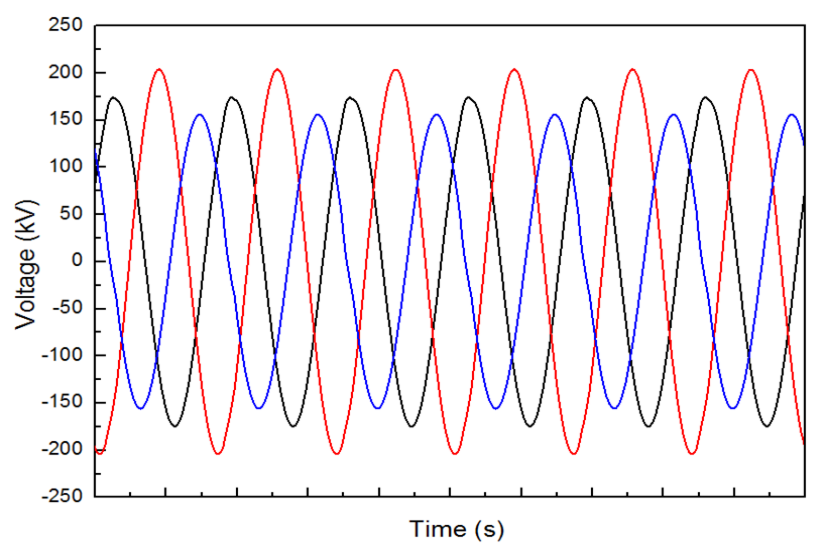

그림 $13 \mathrm{BESS}$ 를 적용하지 않을 경우 3상 전력계통의 전압 Fig. 13 3-phase Voltage of utility grid without BESS

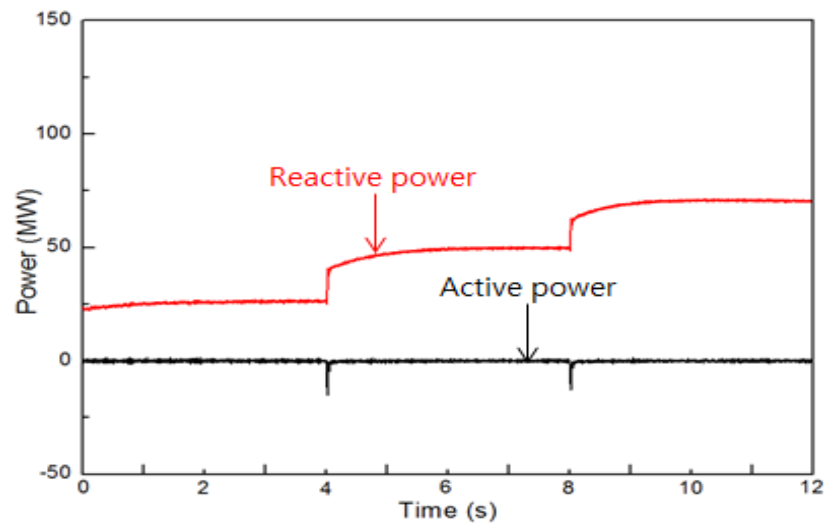

그림 $14 \mathrm{BESS}$ 의 출력

Fig. 14 Output power of BESS

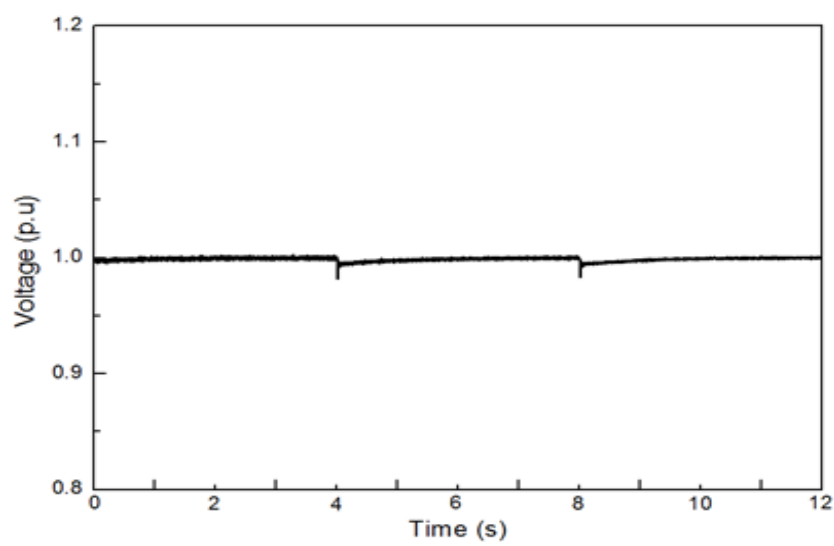

그림 $15 \mathrm{BESS}$ 를 적용할 경우 부하변동에 따른 전압

FIg. 15 Voltage by load change with BESS

또한 전기철도 급전시스템에 $\mathrm{BESS}$ 를 적용할 경우 3 상계 통의 전압 불평형이 그림 16 과 같이 상당부분 완화되는 것 을 확인할 수 있다.

시뮬레이션을 통하여 전기철도의 급전시스템에서 부하가 증가할 경우 급전 계통의 전압강하가 발생되는 것을 확인할 수 있었고, 이러한 전압강하를 보상하기 위하여 $\mathrm{BESS}$ 를 적 
용하였을 때, $\mathrm{BESS}$ 에 의한 무효전력 공급으로 전기철도 급 전시스템의 전압이 1 p.u로 유지되는 것을 확인할 수 있었다. 또한, 각 상의 $\mathrm{BESS}$ 에 의한 전압 유지 효과로 인하여 3상 전력계통의 전압불평형도 상당부분 완화되는 것을 확인할 수 있었다.

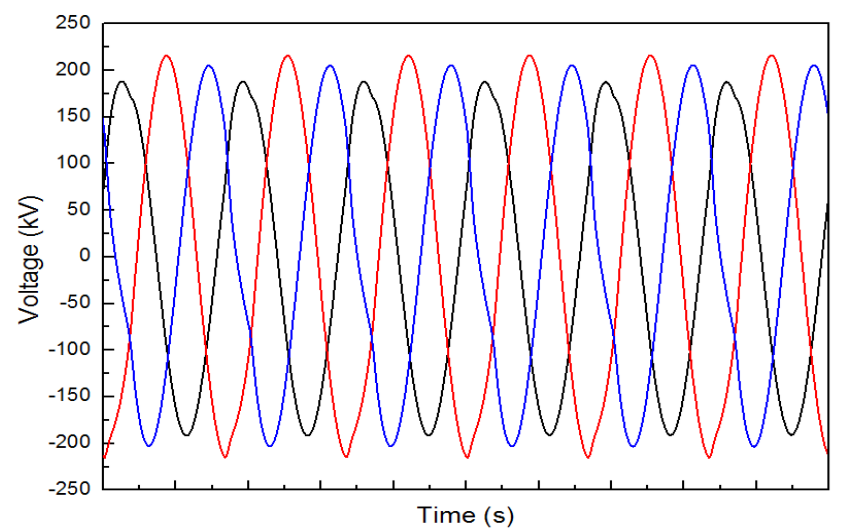

그림 $16 \mathrm{BESS}$ 를 적용할 경우 3상 전력계통의 전압

Fig. 16 Voltage of utility grid with BESS

\section{5. 결 론}

본 논문에서는 Matlab/Simuink를 이용하여 리튬이온 배 터리를 이용한 $\mathrm{BESS}$ 를 모델링하였고, 모델링한 $\mathrm{BESS}$ 를 전 기철도 급전시스템의 전압보상에 적용하기 위하여 스코트변 압기와 단상 $\mathrm{BESS}$ 로 구성된 전기철도 급전시스템을 모델링 하였다. 검토 결과 $\mathrm{BESS}$ 를 적용하지 않은 전기철도 급전시 스템일 경우 단계별 부하증가에 따른 전압강하와 3상 전력 계통의 전압 불평형이 발생되지만 $\mathrm{BESS}$ 를 적용할 경우 부 하가 증가하더라도 전압이 $1 \mathrm{p} . u$ 로 유지되며 3상 전력계통의 전압 불평형이 상당부분 완화되는 것을 확인할 수 있었다.

본 논문에서는 스위치를 이용하여 단계적인 부하를 변동 시키는 부하모델을 이용하였지만 추후 전기철도의 부하패턴 을 이용한 컨버터 기반의 비선형 부하모델을 적용하는 연구 를 수행할 계획이다.

\section{감사의 글}

이 논문은 2012년도 정부(교육과학기술부)의 재원 으로 한국연구재단의 기초연구사업 지원을 받아 수행 된 것임(2012R1A1A1011306).

\section{참 고 문 헌}

[1] Korea Railroad Research Institute, Technical Development for Improvement of Electrical Railway System, 2008

[2] S. H. Lee, H. S. Jung, and J. O Kim, "Analysis for Autotransformer-fed AC Electric Railroad System Using Constant Current Mode," Proc. of The Korean
Society for Railway, pp. 329-334, 2001.

[3] J. S. Kim, J. O Kim, J. K. Lee, and H. S. Jung, "Compensation of Voltage Drop and Improvement of Power Quality at AC railroad System with Single-Phase Distibuted STATCOM," Proc. of KIEE, pp. 192-193, 2006.

[4] H. S. Jung, S. H. Lee, and J O Kim, "Compensate Voltage Drop for Autotransformer-Fed AC Electric Railroad System with Single-Phase STATCOM," Journal of KIIEE, Vol. 16, No. 5, pp. 53-60, 2002.

[5] J. S. Kim, S. H. Lee, J. O Kim, J. K. Lee, and H. S. Jung, "Compensation of Instantaneous Voltage Drop at AC Railroad System with Single-Phase Distributed STATCOM," Journal of KIIEE, Vol. 21, No. 1, pp. 42-51, 2007.

[6] W. Du, Z. Chen, H. F. Wang, and R. Dunn, "Energy Storage Systems Applied in Power System Stability Control," Proc. of Universities Power Engineering Conference, pp. 455-458, 2007.

[7] S. T. Cha, H. Zhao, Q. Wu, A. Saleem, and J. Qstergaard, " Coordinated Control Scheme of Battery Energy Storage System (BESS) and Distributed Generations (DGs) for Electric Distribution Grid Operation," Proc. of 38th Annual Conference on IEEE Industrial Electronics Society, pp. 4758-4764, 2012.

[8] H. Zhou, T. Bhattacharya, D. Tran, T. S. T. Siew, and A. M. Khambadkone, "Composite Energy Storage System Involving Battery and Ultracapacitor with Dynamic Energy Management in Microgrid Application," Trans. of IEEE Power Electronics, Vol. 26, No. 3, pp. 923-930, 2011.

[9] N. M. L. Tan, T. Abe, and H. Akagi, "A 6-kW, 2-kWh Lithium-ion Battery Energy Storage System Using a Bidirectional Isolated DC-DC Converter," Proc. of IPEC, pp. 46-52, 2010.

[10] H. Qian, J. Zhang, and J. S. Lai, "A Grid-Tie Battery Energy Storage System," Proc. of COMPEL, pp. 1-5, 2010.

[11] W. Zhang, D. Dong, L. Cvetkovic, F. C. Lee, and D. Boroyevich, "Lithium-based Energy Storage Management for DC Distributed Renewable Energy System," Proc. of ECCE, pp. 3270-3277, 2011.

[12] I. K. Kang, Electric Railway System Engineering, Sungandang, 2002.

[13] S. D. Kim, and K. H. Kim, "Scott Trnasformer Modeling using PSIM on the AC Substation in the Electric Railroad," Proc. of The Korean Society for Railway, pp. 1892-1897, 2010.

[14] H. S. Jung, M. S. Han, Y. Park, and H. C. Kim, "Analysis of Scott Transformer Winding Method for Unbalanced Voltage Minimizing on Depot," Proc. of KIEE, pp. 233-235, 2010.

[15] O. Ttrmblay, L. A. Dessaint, and A. I. Dekkiche, “ 
A Generic Battery Model for the Dynamic Simulation of Hybrid Electric Vehicles," Proc. of IEEE VPPC, pp. 284-289, 2007.

[16] E. C. Nho, G. B. Jung, and N. S. Choi, Power Electronics, Munundang, 2002.

[17] R. Zhang, M. Cardinal, P. Szczesny, and M. Dame, "A Grid Simulator with Control of Single-Phase Power Converters in $\mathrm{D}^{-\mathrm{Q}}$ Rotating Frame," Proc. of Power Electronics Specialists Conference, Vol. 3, pp. 1431-1436, 2002.

[18] U. A. Miranda, M. Aredes and L.G.B. Rolim, "A DQ Synchronous Reference Frame Control for Single-Phase Converters" Proc. of Power Electronics Specialists Conference, pp. 1377-1481, 2005.

[19] A. Roshan, R. Burgos, A. C. Baisden, F. Wang, and D. Boroyevich, "A D-Q Frame Controller for a Full-Bridge Single Phase Inverter Used in Small Distributed Power Generation Systems," Proc. of Applied Power Electronics Conference, pp. 641-647, 2007.

[20] H. J. Yoo, H. M. Kim, and H. S. Kim, "Basic Modeling and Analysis for AC Railway System based on BTB Voltage Source Converter," KIEE Trans, Vol. 61, No. 11, pp. 1737-1742, 2012.
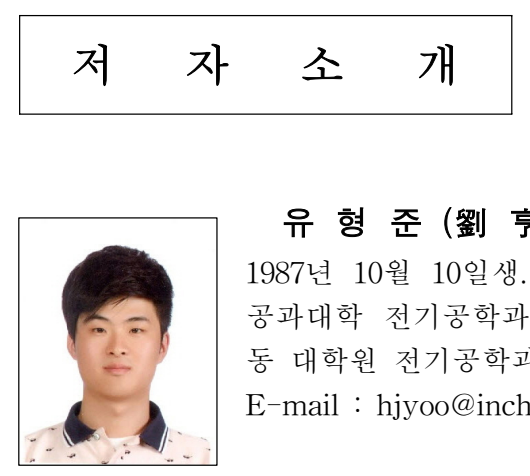

\section{유 형 준 (劉 亨 準)}

1987년 10월 10일생. 2012년 인천대학교 공과대학 전기공학과 졸업, 2012년 현재 동 대학원 전기공학과 석사과정 E-mail : hjyoo@incheon.ac.kr

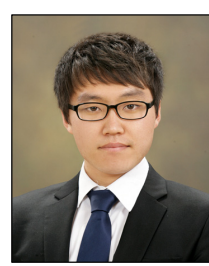

\section{손 호 익 (孫 虎 翼)}

1987년 7월 13일생. 2012년 인천대학교 공과대학 전기공학과 졸업, 2012년 현재 동 대학원 전기공학과 석사과정

E-mail : shi0617@incheon.ac.kr

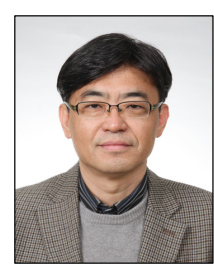

\section{김 학 만 (金 學 萬)}

1966년 2월 11일생. 1998년 성균관대학교 공과대학 전기공학과 졸업(공학박사), 2011년 일본 Tohoku(東北)대학교 정보과 학연구과 졸업(공학박사), 1996년 10월 2008년 2월 한국전기연구원 전력연구 단 선임연구원, 현재 인천대학교 공과대 학 전기공학과 교수.

Tel : 032-835-8769

E-mail : hmkim@incheon.ac.kr 